\title{
Antimicrobial activities of extracts from stem bark of Tagetes minuta
}

\author{
1," Pillai, M.K., ${ }^{1}$ Santi, L.I. and ${ }^{2}$ Mekbib, S.B. \\ ${ }^{I}$ Department of Chemistry and Chemical Technology, Faculty of Science and Technology, National \\ University of Lesotho, Roma Campus, P. O. Roma 180, Kingdom of Lesotho, Southern Africa \\ ${ }^{2}$ Department of Biology, Faculty of Science and Technology, National University of Lesotho, Roma Campus, \\ P. O. Roma 180, Kingdom of Lesotho, Southern Africa
}

\author{
Article history: \\ Received: 11 June 2020 \\ Received in revised form: 1 \\ July 2020 \\ Accepted: 16 July 2020 \\ Available Online: 4 \\ September 2020 \\ Keywords: \\ Tagetes minuta, \\ Asteraceae, \\ Stem bark extracts, \\ Antibacterial activity, \\ Antifungal activity hole-plate \\ diffusion method
}

\section{DOI:}

https://doi.org/10.26656/fr.2017.4(6).279

\begin{abstract}
Tagetes minuta hexane stem bark extract (TMHESB), chloroform stem bark extract (TMCHSB), ethyl acetate stem bark extract (TMEASB) and methanolic stem bark extract (TMMESB) were evaluated for their antimicrobial activities using hole-plate diffusion method. Six bacterial isolates viz. Staphylococcus aureus, Listeria monocytogenes, Escherichia coli (wild), Escherichia coli (O157:H7), Pseudomonas aeruginosa and Serratia marcescens and two fungal isolates viz. Candida albicans and Penicillium digitatum were used for this study. The inhibition zones were found to be in the ranges of $10.0 \pm 1.6$ to $15.5 \pm 1.9 \mathrm{~mm}$ against bacterial isolates and $11.3 \pm 2.1$ to $13.4 \pm 1.2 \mathrm{~mm}$ against $P$. digitatum. However, these extracts did not exhibit any visible inhibition zone against $C$. albicans. Additionally, the minimum inhibitory concentrations (MICs) of these extracts were also determined and was found to be in the range of $<31.25$ to $1000 \mu \mathrm{g} / \mathrm{mL}$. From this study, we concluded that extracts of the stem bark of T. minuta showed a moderate to significant antimicrobial activities. T. minuta has been used in food and beverage industries as preservative, coloring and flavoring agents. T. minuta also finds therapeutic applications in the traditional medicine.
\end{abstract}

\section{Introduction}

Known by other names such as khaki bush, khakhi weed, African marigold and Kakiebos, Tagetes minuta belongs to the Asteraceae family (Ndou and Koekemoer, 2017). T. minuta is native to South America but it is commonly found as widespread weed in Africa, South Europe, South Asia and Australia. T. minuta grows in dry or moist soil and found in areas such as abandoned gardens, farms, roadsides and waste places. T. minuta is an annual herb and has a pleasant smell with stems up to 2-meter tall. T. minuta has stalked light green leaves, which are $7-15 \mathrm{~cm}$ long and pinnately dissected into $4-6$ pairs of pinnae. The leaves bear sunken oil glands with liquorice-like aroma. T. minuta flowers in February, June and November and fruits in December-January, MarchApril and July-September (Ofori et al., 2013). T. minuta is rich in orange-yellow carotenoids (Nerio et al., 2010; Rahimi et al., 2010) and therefore, it has been used as a colorant to make foodstuffs such as pasta, margarine, mayonnaise, salad dressing, confectionery, baked goods, poultry feed and dairy products (Nerio et al., 2010; Rahimi et al., 2010). T. minuta is a good source of essential oil and this essential oil has been used as a flavoring agent in food industries (Nerio et al., 2010; Rahimi et al., 2010). Additionally, T. minuta has been used as a preservative for a wide range of foodstuffs and beverages. T. minuta has several medicinal benefits, which include remedy for colds, respiratory inflammations and stomach problems (Parastoo et al., 2014). T. minuta has also been used as anti-spasmodic, anti-septic and anti-parasitic (Parastoo et al., 2014). T. minuta has been used to cure skin infections, for dilating the bronchi, facilitating the flow of mucus and dislodging congestion (Wang et al., 2006; Govindarajan, 2011; Maity et al., 2011; Nikkon et al., 2011; Aristatile et al., 2013). The decoction from T. minuta has been used as effective control of intestinal parasites in domestic livestock. Roots of $T$. minuta are effective against nematodes, worms, fungi and perennial weeds. $T$. minuta has extensively been used in traditional and complementary medicines. A few articles on the antimicrobial studies of essential oils obtained from the aerial parts of $T$. minuta have previously been reported (Senatore et al., 2004; Gakuubi et al., 2016). However, the antimicrobial activities of extracts from other parts of 
this plant have not been explored well, particularly, the species from the Kingdom of Lesotho. The aim of the present study was to evaluate the antimicrobial activities of hexane, chloroform, ethyl acetate and methanolic extracts from stem bark of $T$. minuta against six bacterial strains viz. Staphylococcus aureus, Listeria monocytogenes, Escherichia coli (wild), Escherichia coli (O157:H7), Pseudomonas aeruginosa and Serratia marcescens and two fungal isolates viz. Candida albicans and Penicillium digitatum. The results are communicated in this article.

\section{Materials and methods}

\subsection{Plant materials}

The stem bark of T. minuta was collected in August 2018 from inside the National University of Lesotho, Roma campus, Lesotho, Southern Africa. A voucher specimen viz. Santi/TMSB/2018 was kept in the Organic Research laboratory, Department of Chemistry and Chemical Technology, Faculty of Science and Technology, National University of Lesotho, Roma campus, Maseru district, Kingdom of Lesotho, Southern Africa.

\subsection{Processing of materials}

The chopped stem bark was allowed to air dry at room temperature (about $22-25^{\circ} \mathrm{C}$ ) for two weeks and ground into powder using a commercial blender (Waring Blender, Blender 80119, Model HGB2WT93, 240V AC, $50-80 \mathrm{~Hz}$, 3.6AMPs, Laboratory and Analytical Supplies).

\subsection{Preparation of plant extracts}

The powdered stem bark (150.172 $\mathrm{g})$ of $T$. minuta was macerated with methanol at room temperature (about $22-25^{\circ} \mathrm{C}$ ) for 3 days with occasional shaking. The solution was filtered using a filter paper (Boeco, Germany). The solvent was removed in vacuo. The procedure was repeated once again. Finally, the same plant material was extracted with methanol under reflux condition for $6 \mathrm{hrs}$. A mass of $5.732 \mathrm{~g}$ of combined methanolic extract was obtained after removal of solvent. The same extraction procedure was followed to get $0.9271 \mathrm{~g}$ of hexane extract, $1.4158 \mathrm{~g}$ of chloroform extract and $4.3107 \mathrm{~g}$ of ethyl acetate extract, respectively from $150.025,150.158$ and $150.421 \mathrm{~g}$ of powdered stem bark.

\subsection{Microorganisms}

The microorganisms used in this study were six bacterial isolates viz. Listeria monocytogenes, Pseudomonas aeruginosa, Escherichia coli (wild), Escherichia coli (O157:H7), Staphylococcus aureus and
Serratia marcescens and two fungal isolates viz. Candida albicans and Penicillium digitatum. All these microorganisms were obtained from the culture collection at the Department of Biology, Faculty of Science and Technology, National University of Lesotho, Roma campus, Maseru district, Kingdom of Lesotho, Southern Africa.

\subsection{Evaluation of antimicrobial activity}

The antimicrobial activities of various extracts from T. minuta were evaluated by in vitro hole-plate diffusion method as described in literature (Manilal et al., 2009; Alghazeer et al., 2012). Briefly, solutions of various extracts were prepared separately at a concentration of $100 \mathrm{mg}$ of extract in $1 \mathrm{~mL}$ of DMSO. The solutions were filtered separately using a $0.20 \mu \mathrm{m}$ filter paper and then used for both antibacterial and antifungal activities. For antibacterial activity, $0.1 \mathrm{~mL}$ of the broth culture was evenly seeded on the Nutrient agar (NA) plates. The agar wells of sizes $4.00 \mathrm{~mm}$ height and $6.00 \mathrm{~mm}$ diameter were punched on the agar plate using a sterile cork-borer. The wells were filled with $30 \mu \mathrm{L}$ aliquots of the extracts. The petri plates were then incubated at $37^{\circ} \mathrm{C}$ for $24 \mathrm{hrs}$. Tetracycline served as a positive control for E.coli (wild), E. coli (HO157), $S$. aureus and $L$. monocytogenes. Amoxicillin served as a positive control for $P$. aeruginosa and $S$. marcescens. DMSO served as a negative control. For the antifungal assay, the petri plates containing $25 \mathrm{~mL}$ of Potato Dextrose Agar (PDA) were used. The agar plates were evenly seeded with $0.1 \mathrm{~mL}$ of the fungi. The holes of sizes $4.00 \mathrm{~mm}$ height and 6.00 $\mathrm{mm}$ diameter were punched using a sterile cork-borer and filled with $30 \mu \mathrm{L}$ aliquots of the extracts. The plates were incubated at $24^{\circ} \mathrm{C}$ for $48 \mathrm{hrs}$. Miconazole nitrate served as a positive control for $C$. albicans. DMSO served as a negative control. However, positive control for $P$. digitatum was not available. The diameter of inhibition zones on the agar surface around the holes was measured to determine the sensitivity of tested microorganisms to the various extracts of $T$. minuta. All experiments were performed in duplicate and results were reported as the mean of two experiments. A clear zones $>10 \mathrm{~mm}$ are considered as positive results (LimaFilho et al., 2002). Inhibition zones of $<12,12-20$ and $\geq 20 \mathrm{~mm}$ diameter are expressed as weak, moderate and strong activities, respectively.

\subsection{Determination of minimum inhibitory concentrations (MICs)}

The MIC value is the minimum concentration of the sample needed to inhibit the growth of the microorganisms (Alghazeer et al., 2012; Alghazeer et al., 2017). The MIC values of $<100 \mu \mathrm{g} / \mathrm{mL}, 100$ to $\leq 625$ $\mu \mathrm{g} / \mathrm{mL}$ and $>625 \mu \mathrm{g} / \mathrm{mL}$ were considered as significantly 
active, moderately active and weakly active, respectively (Emmanuel et al., 2012; Njimoh et al., 2015; Matela et al., 2018). The MIC values were determined as described in the literature (Daud et al., 2005; Alghazeer et al., 2017; Matela et al., 2018). Briefly, a stock solution at a concentration of $1000 \mu \mathrm{g} / \mathrm{mL}$ of various extracts of $T$. minuta was prepared separately. Two-fold serial dilutions such as $1000,500,250,125,62.5$ and $31.25 \mu \mathrm{g} /$ $\mathrm{mL}$ were made from the stock solutions. A suspension of the microorganism was prepared at a concentration of 1 x $10^{6}$ to $2 \times 10^{6}$ colony-forming units (CFU) per $\mathrm{mL}$ by growing the strains in nutrient broth in an incubator with continuous shaking and then used against various extracts as per the method described in literature (Daud et al., 2005). The cylindrical cavities of sizes $4.00 \mathrm{~mm}$ height and $6.00 \mathrm{~mm}$ diameter were punched on the agar plate using a sterile cork-borer and filled with $30 \mu \mathrm{L}$ aliquots of the extracts. The plates were then incubated at $37^{\circ} \mathrm{C}$ for $24 \mathrm{hrs}$ for bacterial species and at $24^{\circ} \mathrm{C}$ for $7-14$ days for fungal species.

\subsection{Statistical analysis}

The statistical analysis was performed using SPSS (ANOVA) statistics program. The differences were considered statistically significant when $\mathrm{p} \leq 0.05$.

\section{Results and discussion}

The antibacterial and antifungal activities of $T$. minuta hexane stem bark extract (TMHESB), T. minuta chloroform stem bark extract (TMCHSB), T. minuta ethyl acetate stem bark extract (TMEASB) and T. minuta methanol stem bark extract (TMMESB) are summarized in Table 1. Against $S$. aureus, TMHESB, TMCHSB, TMEASB and TMMESB showed inhibition zones of $13.5 \pm 2.1, \quad 13.4 \pm 2.0, \quad 12.5 \pm 1.9$ and $12.9 \pm 1.0 \mathrm{~mm}$, respectively. These results showed that all extracts were moderately active and showed relatively weak activity compared to the positive control. The positive control, tetracycline, showed an inhibition zone of $24.5 \pm 0.7 \mathrm{~mm}$. Against L. monocytogenes, TMHESB, TMCHSB, TMEASB and TMMESB showed inhibition zones of $10.7 \pm 1.4, \quad 13.0 \pm 1.9, \quad 12.7 \pm 1.5$ and $13.4 \pm 2.1 \mathrm{~mm}$, respectively. THHESB exhibited weak activity with an inhibition zone of $10.7 \pm 1.4 \mathrm{~mm}$ and all other extracts showed moderate activity with inhibition zones greater than $12.0 \mathrm{~mm}$. However, all four extracts showed relatively weak activity compared to the positive control. The positive control, tetracycline, showed an inhibition zone of $29.5 \pm 0.6 \mathrm{~mm}$. Against $E$. coli (wild), TMHESB, TMCHSB, TMEASB and TMMESB showed inhibition zones of $15.5 \pm 1.9,15.4 \pm 2.1,12.3 \pm 2.7$ and $13.3 \pm 1.0 \mathrm{~mm}$, respectively. This result showed that all extracts were moderately active. Here again, all four extracts showed relatively weak activity compared to the positive control. The positive control, tetracycline, showed an inhibition zone of $20.5 \pm 3.3 \mathrm{~mm}$ against the same bacteria. Against E. coli (O157:H7), TMHESB, TMCHSB, TMEASB and TMMESB showed inhibition zones of 13.3 \pm 2.0 , $10.0 \pm 1.6, \quad 14.3 \pm 1.7$ and $12.3 \pm 2.8 \mathrm{~mm}$, respectively. TMCHSB was weakly active with an inhibition zone of $10.0 \pm 1.6$ while other extracts were moderately active with inhibition zones greater than $12.0 \mathrm{~mm}$. The positive control, tetracycline, showed an inhibition zone of $24.0 \pm 2.0 \mathrm{~mm}$ against the same bacteria. Against $P$. aeruginosa, TMHESB, TMCHSB, TMEASB and

Table 1. Inhibitory effect of hexane, chloroform, ethyl acetate and methanolic extracts from stem bark of T. minuta on selected bacterial and fungal isolates

\begin{tabular}{|c|c|c|c|c|c|}
\hline \multirow{2}{*}{ Microorganisms } & \multicolumn{5}{|c|}{ Extracts/Zones of inhibition (mm) (diameter) } \\
\hline & TMHESB & TMCHSB & TMEASB & TMMESB & Positive Controls \\
\hline \multicolumn{6}{|l|}{ Bacterial isolates } \\
\hline S. aureus & $13.5 \pm 2.1^{\mathrm{a}}$ & $13.4 \pm 2.0^{\mathrm{a}}$ & $12.5 \pm 1.9^{\mathrm{a}}$ & $12.9 \pm 1.0^{\mathrm{a}}$ & $24.5 \pm 0.7^{\mathrm{a}}$ \\
\hline L. monocytogenes & $10.7 \pm 1.4^{\mathrm{a}}$ & $13.0 \pm 1.9^{\mathrm{a}}$ & $12.7 \pm 1.5^{\mathrm{a}}$ & $13.4 \pm 2.1^{\mathrm{a}}$ & $29.5 \pm 0.6^{\mathrm{a}}$ \\
\hline E. coli (wild) & $15.5 \pm 1.9^{\mathrm{a}}$ & $15.4 \pm 2.1^{\mathrm{a}}$ & $12.3 \pm 2.7^{\mathrm{c}}$ & $13.3 \pm 0.9^{\mathrm{a}}$ & $20.5 \pm 3.3^{b}$ \\
\hline E. coli $(\mathrm{O} 157: \mathrm{H} 7)$ & $13.3 \pm 2.0^{\mathrm{a}}$ & $10.0 \pm 1.6^{\mathrm{b}}$ & $14.3 \pm 1.7^{\mathrm{a}}$ & $12.3 \pm 2.8^{\mathrm{b}}$ & $24.0 \pm 2.0^{\mathrm{a}}$ \\
\hline P. aeruginosa & $12.3 \pm 1.6^{\mathrm{a}}$ & $14.2 \pm 2.2^{\mathrm{a}}$ & $13.4 \pm 2.0^{\mathrm{a}}$ & $11.7 \pm 2.4^{\mathrm{b}}$ & $22.5 \pm 2.1^{\mathrm{a}}$ \\
\hline S. marcescens & $13.6 \pm 1.6^{\mathrm{a}}$ & $13.7 \pm 1.4^{\mathrm{a}}$ & $11.4 \pm 1.0^{\mathrm{a}}$ & $10.9 \pm 1.6^{\mathrm{a}}$ & $09.0 \pm 0.0^{\mathrm{a}}$ \\
\hline \multicolumn{6}{|l|}{ Fungal isolates } \\
\hline P. digitatum & $11.3 \pm 2.1^{\mathrm{b}}$ & $13.4 \pm 1.2^{\mathrm{a}}$ & $12.0 \pm 1.5^{\mathrm{a}}$ & $11.9 \pm 1.4^{\mathrm{a}}$ & NT \\
\hline C. albicans & - & - & - & - & $24.5 \pm 1.8^{\mathrm{a}}$ \\
\hline
\end{tabular}

Values with different superscripts in the same column are statistically different at $\mathrm{p}<0.05$. TMHESB $=T$. minuta hexane stem bark extract; TMCHSB $=T$. minuta chloroform stem bark extract; TMEASB $=T$. minuta ethyl acetate stem bark extract; TMMESB $=T$. minuta methanolic stem bark extract. Tetracycline served as a positive control for E. coli (wild), E. coli, (O157:H7), S. aureus and L. monocytogenes. Amoxicillin served as a positive control for P. aeruginosa and S. marcescens. Miconazole nitrate served as a positive control for $C$. albicans. Positive control was not maintained for $P$. digitatum. N/T $=\mathrm{Not}$ Tested. DMSO served as negative control. (-) = inactive. 
TMMESB showed inhibition zones of $12.3 \pm 1.6$, $14.2 \pm 2.2, \quad 13.4 \pm 2.0$ and $11.7 \pm 2.4 \mathrm{~mm}$, respectively. These results showed that TMMESB was weakly active with an inhibition zone of $11.7 \pm 2.4 \mathrm{~mm}$ while all other extracts were moderately active. The positive control, amoxicillin, showed an inhibition zone of $22.5 \pm 2.1 \mathrm{~mm}$. Against $S$. marcescens, TMHESB, TMCHSB, TMEASB and TMMESB showed inhibition zones of $13.6 \pm 1.6$, $13.7 \pm 1.4,11.4 \pm 1.0$ and $10.9 \pm 1.6 \mathrm{~mm}$, respectively. TMEASB and TMMESB exhibited weak activity with inhibition zones of $11.4 \pm 1.0$ and $10.9 \pm 1.6 \mathrm{~mm}$, respectively while TMHESB and TMCHSB were moderately active with inhibition zones greater than $12 \mathrm{~mm}$. The positive control, amoxicillin, showed an inhibition zone of $9.0 \pm 0.0 \mathrm{~mm}$. In general, all extracts exhibited activity against all six bacterial isolates but their relative activity varied from one extract to another as shown in Table 1. Against $P$. digitatum, TMHESB, TMCHSB, TMEASB and TMMESB showed inhibition zones of $11.3 \pm 2.1,13.4 \pm 1.2,12.0 \pm 1.5$ and $11.9 \pm 1.4 \mathrm{~mm}$, respectively. This result showed that TMHESB and TMMESB were weakly active with inhibition zones of $11.3 \pm 2.1$ and $11.9 \pm 1.4 \mathrm{~mm}$, respectively while TMCHSB and TMEASB showed moderate activity with inhibition zones of $13.4 \pm 1.2$ and $12.0 \pm 1.5 \mathrm{~mm}$, respectively. Against C. albicans, these four extracts did not exhibit any visible inhibition zones while the positive control, miconazole nitrate showed an inhibition zone of $25.8 \pm 1.8 \mathrm{~mm}$.

The minimum inhibition concentrations (MICs) of various extracts of T. minuta are summarized in Table 2 . The MIC values of TMHESB and TMCHSB were found to be $62.5 \mu \mathrm{g} / \mathrm{mL}$ for each extract against $S$. aureus. However, TMEASB and TMMESB exhibited MIC values of 125 and $<31.25 \mu \mathrm{g} / \mathrm{mL}$, respectively against the same bacterial isolates. The MIC value of TMCHSB and TMEASB was found to be $<31.25 \mu \mathrm{g} / \mathrm{mL}$ for each extract while the MIC values of TMHESB and TMMESB were found to be $>1000$ and $125 \mu \mathrm{g} / \mathrm{mL}$, respectively against $L$. monocytogenes. The MIC value of TMHESB, TMCHSB and TMMESB was found to be $<31.25 \mu \mathrm{g} / \mathrm{mL}$ for each extract against $E$. coli (wild) while TMEASB exhibited MIC value of $62.5 \mu \mathrm{g} / \mathrm{mL}$ against the same bacterial isolates. The MIC values of TMHESB, TMCHSB, TMEASB and TMMESB were found to be $125,1000,<31.25$ and $250 \mu \mathrm{g} / \mathrm{mL}$, respectively against $E$. coli (O157:H7). The MIC values of TMHESB, TMCHSB, TMEASB and TMMESB were found to be $250,62.5,125$ and $250 \mu \mathrm{g} / \mathrm{mL}$, respectively against $P$. aeruginosa. The MIC value of $<31.25 \mu \mathrm{g} / \mathrm{mL}$ was found for TMHESB and TMCHSB for each extract against $S$. marcesens while TMEASB and TMMESB exhibited MIC value of $500 \mu \mathrm{g} / \mathrm{mL}$ for each extract. The MIC values of TMHESB, TMCHSB, TMEASB and TMMESB were found to be $500,<31.25,250$ and 125 $\mu \mathrm{g} / \mathrm{mL}$, respectively against $P$. digitatum. The MIC assay against $C$. albicans was omitted since all extracts showed no visible inhibition zone in the preliminary study (Table $1)$.

Essential oils obtained from aerial parts of T. minuta collected in Egypt, South Africa and the UK have previously been evaluated for their antimicrobial activity against eight bacterial isolates viz. Bacillus cereus, Bacillus subtilis, Staphylococcus aureus, Streptococcus faecalis, E. coli, Proteus mirabilis, P. aeruginosa and Salmonella enterica serovar Typhi (Senatore et al., 2004). The essential oils from plants of the UK showed higher inhibition zones than the essential oils from the plants of Egypt and South Africa (Senatore et al., 2004). Additionally, the MICs for the essential oils from plants of the UK were found to be $6.25-25.0 \mu \mathrm{g} / \mathrm{mL}$ for Grampositive bacteria and $25.0-50.0 \mu \mathrm{g} / \mathrm{mL}$ for Gramnegative bacteria with the lowest MIC of $6.25 \mu \mathrm{g} / \mathrm{mL}$ against $S$. faecalis. However, the essential oils from

Table 2. The minimum inhibitory concentrations (MICs) of hexane, chloroform, ethyl acetate and methanolic extracts from stem bark of T. minuta on selected bacterial and fungal isolates.

\begin{tabular}{|c|c|c|c|c|}
\hline \multirow{2}{*}{ Microorganisms } & \multicolumn{4}{|c|}{ Extracts/Minimum inhibition concentrations (MICs) $(\mu \mathrm{g} / \mathrm{mL})$} \\
\hline & TMHESB & TMCHSB & TMEASB & TMMESB \\
\hline \multicolumn{5}{|l|}{ Bacterial isolates } \\
\hline S. aureus & 62.5 & 62.5 & 125 & $<31.25$ \\
\hline L. monocytogenes & $>1000$ & $<31.25$ & $<31.25$ & 125 \\
\hline E. coli (wild) & $<31.25$ & $<31.25$ & 62.5 & $<31.25$ \\
\hline E. coli $(\mathrm{O} 157: \mathrm{H} 7)$ & 125 & 1000 & $<31.25$ & 250 \\
\hline P. aeruginosa & 250 & 62.5 & 125 & 250 \\
\hline S. marcescens & $<31.25$ & $<31.25$ & 500 & 500 \\
\hline \multicolumn{5}{|l|}{ Fungal isolates } \\
\hline$P$. digitatum & 500 & $<31.25$ & 250 & 125 \\
\hline C. albicans & $\mathrm{N} / \mathrm{T}$ & $\mathrm{N} / \mathrm{T}$ & $\mathrm{N} / \mathrm{T}$ & $\mathrm{N} / \mathrm{T}$ \\
\hline
\end{tabular}

TMHESB $=T$. minuta hexane stem bark extract; TMCHSB $=T$. minuta chloroform stem bark extract; TMEASB $=T$. minuta ethyl acetate stem bark extract; TMMESB $=T$. minuta methanolic stem bark extract, N/T $=$ Not Tested. DMSO served as negative control. 
plants of South Africa showed MICs of 50.0-100 $\mu \mathrm{g} / \mathrm{mL}$ against both Gram-positive and Gram-negative bacteria. The MICs of the essential oils from plants of Egypt were found to be 100 and $50.0 \mu \mathrm{g} / \mathrm{mL}$, respectively against $P$. aeruginosa and Salmonella enterica serovar Typhi. Against the other six bacterial isolates, these essential oils from the plants of Egypt showed lower MIC values than essential oils from the plants of South Africa (Senatore et al., 2004). The antimicrobial activity of aerial parts of essential oils of T. minuta collected from Maseno area of Kenya were also evaluated against Pseudomonas savastanoi pv. Phaseolicola (PSP), Xanthomonas axonopodis pv. Phaseoli (XAP) and Xanthomonas axonopodis pv. Manihotis (XAM) (Gakuubi et al., 2016). The inhibition zones were found to be $26.83 \pm 0.60,26.83 \pm 0.17$ and $41.83 \pm 0.93 \mathrm{~mm}$ for XAP, XAM and PSP, respectively. The MICs values were found to be 12,24 and $48 \mathrm{mg} / \mathrm{mL}$ for PSP, XAP and XAM, respectively. Our literature search showed that extracts from stem bark of T. minuta have not previously been reported. To the best of our knowledge, this is the first report of this kind, particularly, the species from the Kingdom of Lesotho.

\section{Conclusion}

We evaluated antibacterial and antifungal activities of hexane, chloroform, ethyl acetate and methanolic extracts from stem bark of $T$. minuta. Six bacterial isolates viz. S. aureus, L. monocytogenes, E. coli (wild), E. coli (O157: H7), P. aeruginosa and $S$. marcescens and two fungal isolates viz. $C$. albicans and $P$. digitatum were used in this study. The zones of inhibition were found to be in the range $10.0 \pm 1.6$ to $15.5 \pm 1.9 \mathrm{~mm}$ against bacterial isolates and $11.3 \pm 2.1$ to $13.4 \pm 1.2 \mathrm{~mm}$ against $P$. digitatum. However, these extracts did not exhibit any visible inhibition zones against $C$. albicans. Additionally, the minimum inhibitory concentrations (MICs) of these extracts were also evaluated and was found to be in the range of $<31.25$ to $>1000 \mu \mathrm{g} / \mathrm{mL}$. To conclude, T. minuta showed a moderate to significant antibacterial and antifungal activities. T. minuta has been used in food and beverage industries as preservative, coloring and flavoring agents. T. minuta also finds therapeutic applications in the traditional medicine.

\section{Conflict of interest}

The authors declare that there is no conflict of interests.

\section{Acknowledgements}

The authors would like to acknowledge the National University of Lesotho for its overall support.

\section{References}

Alghazeer, R., El-Saltanil, H., Saleh, N., Al-Najjar, A. and Hebail, F. (2012). Antioxidant and antimicrobial properties of five medicinal Libyan plants extracts. Natural Science, 4(5), 324-335. https:// doi.org/10.4236/ns.2012.45045

Alghazeer, R., Elmansori, A., Sidati, M., Gammoudi, F., Azwai, S., Naas, H., Garbaj, A. and Eldaghayes, I. (2017). In vitro antibacterial of flavonoid extracts of two-selected Libyan Algae against multi-drug resistant bacteria isolated from food products. Journal of Biosciences and Medicine, 5(1), 26-48. https://doi.org/10.4236/jbm.2017.51003

Aristatile, B., Al-Assaf, A.H. and Pugalendi K.V. (2013). Carvacrol suppresses the expression of inflammatory marker genes in D-galactosamine-hepatotoxic rats. Asian Pacific Journal of Medicine, 6(3), 205-211. https://doi.org/10.1016/S1995-7645(13)60024-3

Daud, A., Gallo, A. and Sanchez, A. (2005). Antibacterial properties of Phrygilanthus acutifolius. Journal of Ethnopharmacology, 99(2), 193-195. https://doi.org/10.1016/j.jep.2005.01.043

Njimoh, D.L., Assob, J.C.N., Mokake, S.E., Nyhalah, D.J., Yinda, C.K. and Sandjon, B. (2015). Antimicrobial activities of a plethora of medicinal plant extracts and hydrolates against hum pathogens and their potential to reverse antibiotic resistance. International Journal of Microbiology, 2015, 547156. https://doi.org/10.1155/2015/547156

Emmanuel, M.T., Anatole, C.P. and Veronique, P.B. (2012). Investigations of antimicrobial activity of some Cameroonian medicinal plant extracts against bacteria and yeast with gastrointestinal relevance. Journal of Ethnopharmacology, 142(1), 265-273. https://doi.org/10.1016/j.jep.2012.05.005

Gakuubi, M.M., Wagacha, J.M., Dossaji, S.F. and Wanzala, W. (2016). Chemical Composition and Antimicrobial activity of Essential oils of Tagetes minuta (Asteraceae) against selected plant pathogenic Bacteria. International Journal of Microbiology, 2016, 7352509. https:// doi.org/10.1155/2016/7352509

Govindarajan, M. (2011). Larvicidal and repellent properties of some essential oils against Culex tritaeniorhyncuus Giles and Anopheles subpictus Grassi (Diptera: Culiciole). Asian Pacific Journal of Tropical Medicine, 4, 106-111. https:// doi.org/10.1016/S1995-7645(11)60047-3

Lima-Filho, M., Carvalho, U. and Freitas, M. (2002). Antibacterial activity of extracts of six Macroalgae from the Northeastern Brazilian Coast. Brazilian Journal of Microbiology, 33(4), 311-313. https:// 
doi.org/10.1590/S1517-83822002000400006

Maity, N., Nema, N.K., Abedy, M.K., Sarkar, B.K. and Mukherjee, P.K. (2011). Exploring Tagetes erecta Linn flower for the elastase, hyaluronidase and MMP-1 inhibitory activity. Journal of Ethnopharmacology, 137(3), 1300-1305. https:// doi.org/10.1016/j.jep.2011.07.064

Manilal, A., Sujith, S., Kiran, G.S., Seivin, J., Shakir, C., Gandhimathi, R. and Panokkar, M.V.N. (2009). Biopotentials of seaweeds collected from southwest coast of India. Journal of Marine Science and Technology, 17(1), 67-73.

Matela K.S., Mekbib, S.B. and Pillai, M.K. (2018). Antimicrobial activities of extracts from Gleditsia triacanthos L. and Schinus Molle L. Pharmacologyonline, 2, 85-92.

Ndou, M. and Koekemoer, M. (2017). Tagetes minuta. Retrieved from South African National Biodiversity Institute website: http://pza.sanbi.org/tagetes-minuta

Nerio, L.S., Olivero-Verbal, J. and Stashenko, E. (2010). Repellent activity of essential oils: a review. Bioresource Technology, 101(1), 372-378. https:// doi.org/10.1016/j.biortech.2009.07.048

Nikkon, F., Habib, M.R., Suad, Z.A. and Karim. M.R. (2011). Tagetes erecta and its mosquitocidal potency against Culex quinquefasciatus. Asian Pacific Journal of Tropical Biomedicine, 1(3), 186-188. https://doi.org/10.1016/S2221-1691(11)60024-5

Ofori, D.A., Anjarwalla, P., Mwaura, L., Jamnadass. R., Stevenson, P.C. and Smith, P. (2013). Pesticidal plant leaflet: Tagetes minuta L. Retrieved from World Agroforestry center website: http:// blog.worldagroforestry.org/wp-content/uploads/ PDFs/Pesticidal-Plant-Leaflets-Full-Set.pdf

Parastoo, K., Kavoosi, G. and Zahra, A. (2014). Antioxidative and anti-inflammatory effects of Tagetes minuta essential oil in activated macrophages. Asian Pacific Journal of Tropical Biomedicine, 4(3), 219-227. https://doi.org/10.1016/ S2221-1691(14)60235-5

Rahimi, R., Shams-Ardekani, M.R. and Abdollahi, M.A. (2010). A review of the efficacy of traditional Iranian medicine for inflammatory bowel disease. World Journal of Gastroenterology, 16(36), 45044514. https://doi.org/10.3748/wjg.v16.i36.4504

Senatore, F., Napolitano, F., A-H Mohamed, M., Harris, P J.C., Mnkeni, P.N.S. and Henderson, J. (2004). Antimicrobial activity of Tagetes minuta L. (Asteraceae) essential oil with different chemical composition. Flavour and Fragrance Journal, 19(6), 574-578. https://doi.org/10.1002/ffj.1358

Wang, M., Tsao, R., Zhang, S., Dong, Z., Yang, R.,
Gong, J. and Pei, Y. (2006). Antioxidant activity, mutagenicity/anti-mutagenicity, and Clastogenicity/ anti-clastogenicity of lutein from marigold flowers. Food and Chemical Toxicology, 44(9), 1522-1529. https://doi.org/10.1016/j.fct.2006.04.005 